\title{
PREDICTION OF MATERIAL REMOVAL RATE USING REGRESSION ANALYSIS AND ARTIFICIAL NEURAL NETWORK OF ECDM PROCESS
}

\author{
Sathisha $N,{ }^{1}$ Somashekhar S. Hiremath ${ }^{2}$ and Shivakumar $\mathrm{J}^{3}$

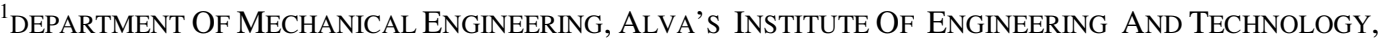 \\ MOODABIDRI, MANGALORE,- 574 225, INDIA \\ ${ }^{2}$ DEPARTMENT OF MECHANICAL ENGINEERING, INDIAN INSTITUTE OF TECHNOLOGY MADRAS, \\ CHENNAI- 600036, INDIA \\ ${ }^{3}$ DEPARTMENT OF MECHANiCAl ENGINEERING, CHhATTISGARH ENGINEERING COLlEGE, DurG, \\ CHHATTISGARH- 491001, INDIA
}

\begin{abstract}
The combination of two non conventional machining processes is known as Hybrid machining. It has become one of the most important machining techniques for glass and other brittle materials. In this paper, an attempt has been made to combine Electro Chemical machining(ECM) and Electrical Discharge Machining (EDM) to form a hybrid machining known as Electro Chemical Discharge Machining (ECDM). It can be applied for micro machining and micro finishing on the glass and its composites. The empirical models have been developed for grooving process of ECDM using Regression Analysis (RA) and the Artificial Neural Network (ANN) to predict the Material Removal Rate (MRR). According to results, the prediction of ANN model for MRR is better as compared to the Regression model. The two models of ECDM process can be recommended to predict the MRR for grooving of ECDM for the given range of process parameters. The process parameters of the ECDM process are optimized. ANOVA is used to identify the significant affect of process parameters.
\end{abstract}

\section{KEYWORDS}

Hybrid process, ECDM, MRR, Regression Analysis, ANN, ANOVA

\section{INTRODUCTION}

The machining of brittle and hard materials is a challenging task to the manufacturers. On the contrary, such materials are difficult to machine by Conventional machining methods. The non conventional machining methods are suitable for such materials like Glass, Ceramics, and granite etc. Electro Discharge Machining (EDM) and Electro Chemical Machining (ECM) are plays a vital role to machine conducting materials but are not suitable for non-conductive materials. This has lead to the development of hybrid machining technology to machine conductive and nonconductive materials. Electro Chemical Discharge Machining (ECDM) is one of the hybrid technologies that combine the principles of ECM and EDM to machine non-conductive materials. Some of the main literature findings on the ECDM process are as follows.

The mechanism of spark generation during ECDM process was investigated by Basak and Ghosh [1].They developed an experimental setup to machine non- conductive materials and proposed a theoretical model. Using theoretical model, critical parameters like voltage and current are estimated and noticed that the discharge phenomenon is corresponding to a control of an electric 
circuit. Gautam and Jain [2] have conducted experiments on borosilicate glass and quartz workpiece materials using various tool kinematics like stationary, rotational and eccentrically rotating tool to enhance the process capabilities. It has been discussed that the ECDM process has more advantages when tool is feed with constant velocity mechanism over gravity feed mechanism. Bhattacharyya et al. [3] has carried out experimental investigations to machine nonconducting ceramic materials using ECDM and also discussed the influence of the tool tip geometrical shape for greater machining rate. It was discovered that the tapered side wall and flat front tool tip shape was found to be most effective for controlled machining to produce perfectly circular holes. The different shapes of tools can be used in ECDM process as per the shape to be produced on work material. The various shape of tool like square cross-section with centrally micro hole were used for micro ECSM of electrically non conductive glass-fibre- reinforced composites [4]. Dae-Jin Kim et al. [5] have carried out the experimental investigation to study the effect of the frequency and duty ratio of the voltage pulse on the ECDM process for machining on Pyrex glass. It is also reported that the thermal damage of the micro drilled hole decreases as the frequency increases and the duty ratio decreases. The slicing of thin optical glass, engineering ceramics and composite material with horizontal wire set-up using Wire-ECDM is investigated [6]. Singh et al. [7] investigated the feasibility of Electrochemical Spark Machining (ECSM) process for partially conductive materials like piezoelectric ceramics and carbon fibre epoxy composites. Liu et al.[8] discussed the prediction of the critical breakdown voltage of the hydrogen bubble in ECDM process for a particulate reinforced metal matrix composite by developing the model of discharge mechanism. The Electro Chemical Spark Machining process (ECSM) is successfully applied for cutting of quartz using a controlled feed and a wedge edged tool by Jain and Adhikary [9]. Several experiments are carried out to explain the mechanism of the spark generation by Kulkarni et al. [10]. They are also discussed that the synchronized and transient measurements revealed the discrete nature of the ECDM process by developing a theoretical model of ECDM process. Fascio et al. [11] proposed two theoretical models of Spark Assisted Chemical Engraving (SACE) phenomenon which is same as ECDM phenomenon. First model based on percolation theory and second model is used to estimate the spark's characteristics. Wüthrich et al. [12 ]have discussed about various tool feeding mechanisms of SACE micro-hole drilling on glass using stainless steel tool electrode of $0.4 \mathrm{~mm}$ diameter with gravity tool feed and noticed that no tool wear during machining. Sanjay and Venkateswara Rao [13] have conducted an experiment on aluminum oxide with diamond abrasive rotating tool to enhance the machining ability using ECDM process. They also revealed that the used tool was better than the hollow stationary electrode for better MRR. It reported the ECDM fundamentals and technology for machining of micro holes in borosilicate glass and partly in diamond crystals [14].

The ECDM gives another chance to reduce some machining problems under condition of precise selection and control of the process means. Schopfet al. [15] have successfully applied ECDM technology on a centerless grinding machine for truing and dressing of metal bonded diamond tools and hence for the grinding of new cutting materials (Cermets, Ceramics, PCD). Debasish Nandi et al. [16] reports that the behaviour of bubbles formed around the electrodes in ECDM process as a factor of spark initiation. The various alkaline solutions $(\mathrm{NaOH}$ and $\mathrm{KOH})$ are used as electrolyte in ECDM by Xuon Doan Cao et al.[17] and also observed that the KOH electrolyte provides a lesser machining gap than $\mathrm{NaOH}$ solution which results in increase of MRR. Raghuram et al [18] have studied the relationship between voltage and current in different kinds of electrolytes like $\mathrm{NaOH}, \mathrm{KOH}$ and $\mathrm{HCl}$ with varying concentrations and explained that the material removal rate is affected by the process parameters and analyzed experimentally with different combinations of the electrolytes, tool diameter and tool depth. Jana et al. [19] reported that ECDM can be used to machine the surface texture of glass and micro-channels. It is also proved that the stand of distance (SOD) influences the depth of the micro-channels. The spherical end tool electrode is introduced by Cheng-Kuanget al. [20] and reported that the curved surface of 
the electrode reduces the contact area between the tool and the workpiece which results in increasing the discharge frequency and reducing the machining time.

The empirical mathematical model has been developed to show the influence of process parameters on the electrode tool wear, MRR, and accuracy of the machined hole by Coteaţăet al.[21]. Min-Seop Han et al. [22] proposed a new type of micro-ECDM cutting tool, utilizing for surface texturing. This method was experimentally verified by cutting soda-lime glass with a thickness of $0.4 \mathrm{~mm}$ with improved surface integrity.

The taguchi orthogonal array is very popular for the optimization of process parameters in manufacturing engineering. The ANOVA has been employed successfully in process optimization and identification of significant parameters which effect on surface roughness in end milling [23]. It is reported that the modified Taguchi robust design and Utility concept can be applied to determine optimal combination of process parameters to machine soda lime glass using abrasive hot air jet machining [24]. ANNs have been widely applied in modelling many metal cutting operations, such as turning, milling and drilling [25]. The ANN and Regression Analysis (RA) are presented for the prediction of tool-chip interface temperature which depends on cutting parameters in machining [26]. The development of the hybrid model to optimize the surface roughness in electric discharge machining using Artificial Neural Networks and genetic algorithms is proposed by Rao et al [27]. Mediliyegedara et al. [28] have developed a control strategy for ECDM process using ANN and it was trained to classify pulses with various activation functions.

In this paper, an experimental setup of ECDM has been developed to machine soda lime glass. Experiments were conducted using taguchi's orthogonal array to reduce the number of experiments. The regression and ANN models are developed to predict the Material Removal Rate. The statistical tool ANOVA has been employed to optimize the process parameters which affects the MRR. The comparison of the developed models with experimental results is also discussed.

\section{EXPERIMENTAL SETUP}

The schematic diagram of developed experimental setup is as shown in Fig .1, It consists of tool electrode (Cathode of stainless steel needle of diameter $0.6 \mathrm{~mm}$ ), auxiliary anode of zinc plate (size $100 \mathrm{~mm} \times 60 \mathrm{~mm} \times 1.0 \mathrm{~mm}$ ), tool feeding mechanism, electrolyte container, workpiece holder, power supply unit and two axes work table with CNC controller. The vertical movement of the tool is controlled by tool feeding unit with micro controller. The SOD is adjusted using filler gauges and tool feeding unit. The movement of workpiece is controlled by $\mathrm{X}-\mathrm{Y}$ table with $\mathrm{CNC}$ controller. In this work, different kinds of electrolytes with different concentrations were used. Experiments were conducted to machine the holes and channels on soda lime glass by varying SOD, voltage and electrolyte concentration.

The experiments were conducted using Taguchi orthogonal array. The modeling of ECDM has been carried out using RA and ANN techniques based on the experimental results. The correlation between experimental results with models has been discussed. The parameters were optimized using ANOVA. The confirmation test has been conducted to verify the results.

In the present work, soda-lime glass was used as the work material and the specimens of size (50 $\mathrm{mm} \times 20 \mathrm{~mm} \times 1.5 \mathrm{~mm}$ ) are selected for conducting the experiment Specimens were weighed before machining. The samples were cleaned after machining and final weight was measured using a digital electronic balance with a resolution of $0.1 \mathrm{mg}$. The amount of material removed was measured by taking difference in weight of the specimen before machining and after machining weight. 


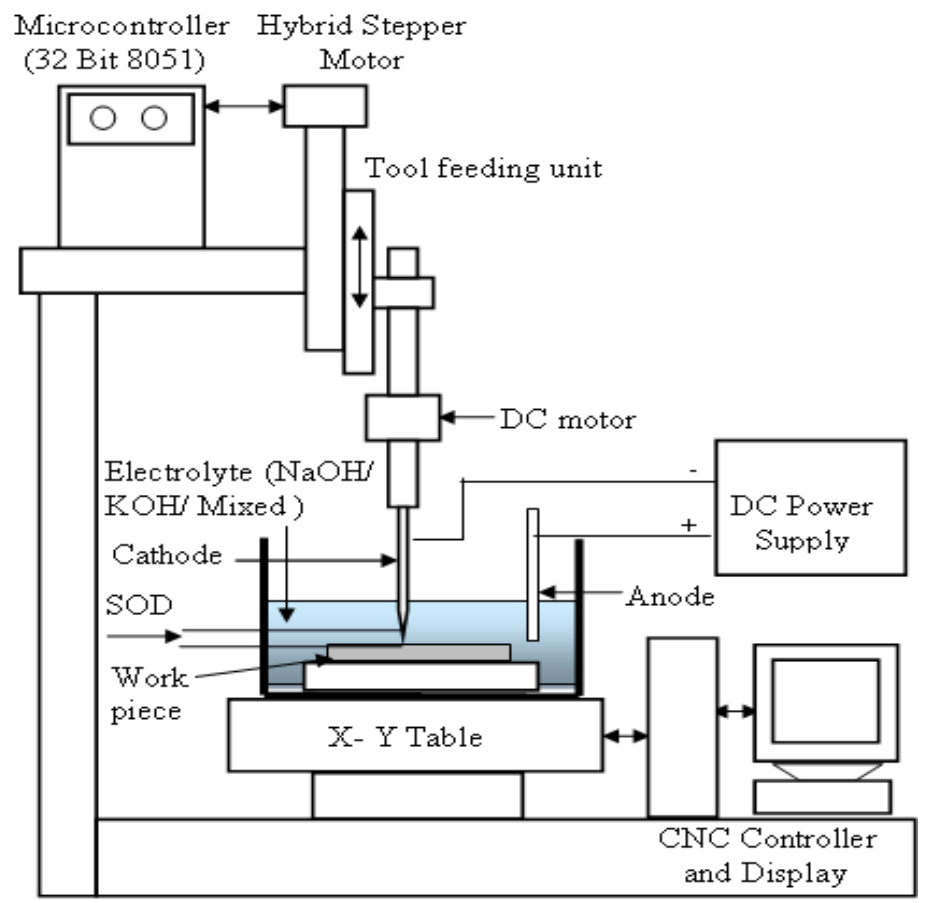

Fig. 1 Schematic diagram of ECDM Setup

The ECDM process involves more number of variables. For the purpose of present investigation, only major variables like Stand Off Distance (SOD), concentration of electrolyte and voltage were considered. The experimental parameters like feed rate, distance between cathode (tool) and auxiliary anode (zinc plate), tool size are kept constant throughout the machining process. The process parameters and their levels are shown in Table. 1.

Table. 1 Process parameters and their levels

\begin{tabular}{|l|l|c|c|c|}
\hline & Process parameters & Level 1 & Level 2 & Level 3 \\
\hline A & Concentration of Electrolyte (weight \%) & 10 & 20 & 30 \\
\hline B & Voltage (volts) & 40 & 50 & 60 \\
\hline C & SOD (mm) & 0.03 & 0.05 & 0.07 \\
\hline
\end{tabular}

\section{RESULTS AND DISCUSSIONS}

\subsection{Development of Regression model for MRR}

Regression Analysis is a statistical tool for the investigation of relationships between variables. It is one of the commonly used techniques in predicting the output characteristics. Multiple Regression Analysis (MRA) is applied to determine the relationship between the predictor variables and criterion variables [29]. It can be generally expressed as

$$
y=\beta_{0}+\beta_{1} X_{1}+\beta_{2} X_{2}+\beta_{3} X_{3}
$$

Where $y$ is criterion variable (MRR) $, X_{1}, X_{2}$ and $X_{3}$ are predictor variables (Concentration of Electrolyte, Voltage and SOD) $\beta_{0,} \beta_{1}, \beta_{2}$ and $\beta_{3}$ are regression coefficients 
The general regression model can be written in matrix notation using Equation (2) as given below,

$$
y=X \beta+\varepsilon
$$

The solution for the regression coefficients are given by Equation (3),

$$
b=\left(X^{\prime} X\right)^{-1} X^{\prime} y
$$

Statistical software MINITAB 16 was used to develop a Regression model for predicting MRR. The matrix is formulated based on the proposed regression Equation (1). It is solved to compute regression coefficients and these coefficients are used to estimate the MRR. The experimental data are used to perform regression analysis and the numerical values of coefficients are determined. The modified Equation (4) of first order regression model is used for prediction of MRR as a function of process parameters (A, B, and C).

$$
M R R=0.0261+0.000813 A+0.000628 B-0.468 C
$$

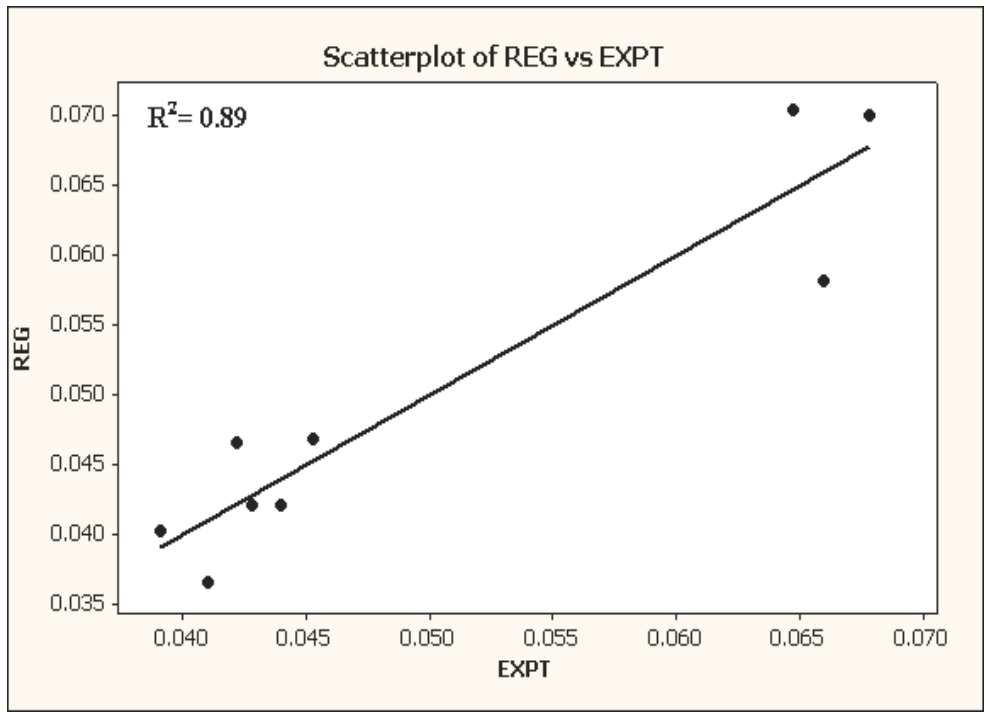

Fig.2 Comparison of predicted MRR with experimental MRR

The predicted MRR values using regression equation are given in Table 2. The prediction model is verified against the data obtained from the experiments and the comparison is illustrated in Fig.2. The results obtained from the model are very close to that of experiments conducted (Table 2). The error can be calculated using Equation (5). It can be found that the predicted values and experimental values have very less deviation. The average deviation is estimated as $6.48 \%$. It is clear that the experimental data agree very well with predictions. Therefore, the Regression model can be used to estimate the MRR for machining of soda lime glass using ECDM.

$$
\text { Error }=\frac{1}{n} \sum_{n}\left[\frac{M R R_{\text {exp }}-M R R_{\text {pred }}}{M R R_{\text {exp }}}\right] \%
$$


Table .2 Comparison of Predicted (MRR) values with Experimental results

\begin{tabular}{|c|c|c|c|}
\hline $\begin{array}{c}\text { Expt. } \\
\text { No. }\end{array}$ & $\begin{array}{c}\text { Experimental } \\
\text { MRR } \\
(\mathbf{g} / \mathbf{m i n})\end{array}$ & $\begin{array}{c}\text { Regression } \\
\text { Model } \\
\text { MRR } \\
(\mathbf{g} / \mathbf{m i n})\end{array}$ & $\begin{array}{c}\text { Error } \\
(\boldsymbol{\%})\end{array}$ \\
\hline 1 & 0.0469 & 0.0453 & 3.39 \\
\hline 2 & 0.0466 & 0.0422 & 9.37 \\
\hline 3 & 0.0402 & 0.0391 & 2.61 \\
\hline 4 & 0.0421 & 0.0440 & -4.70 \\
\hline 5 & 0.0366 & 0.0410 & -12.02 \\
\hline 6 & 0.0582 & 0.0660 & -13.40 \\
\hline 7 & 0.0421 & 0.0428 & -1.78 \\
\hline 8 & 0.0700 & 0.0678 & 3.07 \\
\hline 9 & 0.0704 & 0.0647 & 7.99 \\
\hline
\end{tabular}

\subsection{Development of ANN model for MRR}

Experimental results were used to develop an ANN model for predicting MRR. In this work, three inputs and one output are considered as the data of ANN model. Input variables electrolyte concentration, voltage and SOD. The output variable was MRR. The 18 results obtained from the experiments were used in training the network and 9 results were used for testing. Many network architectures were tried. The multilayer perception network structure which yielded the best results was used. The chosen network structure (3-4-4-1) is shown in Fig.3.

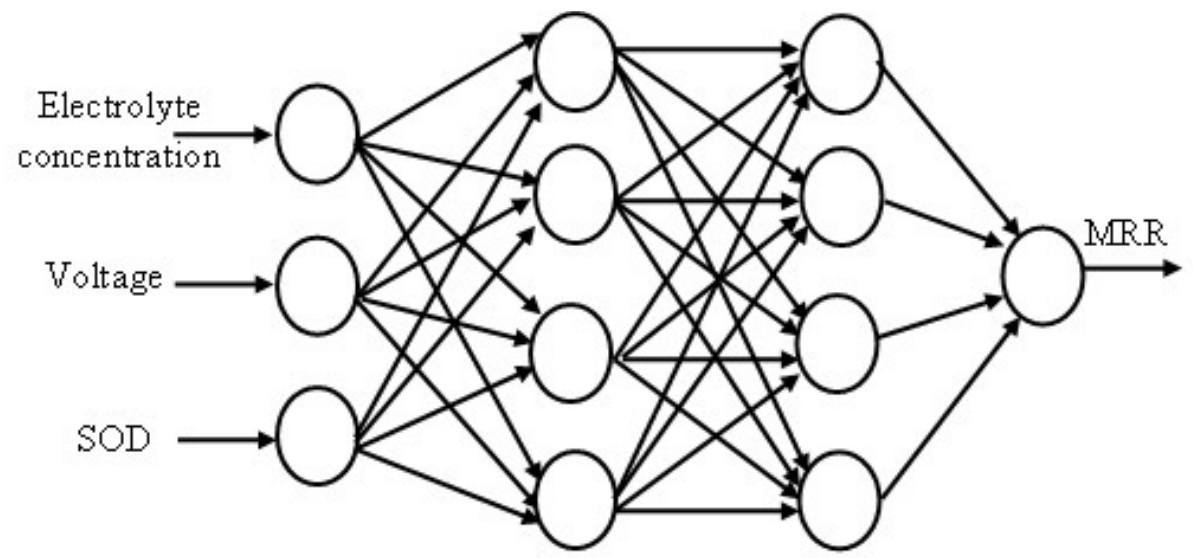

Fig.3 Architecture of Multilayer ANN (3-4-4-1)

Performance of the network is determined with MSE which should be minimized. MSE is calculated with the help of Equation (6). Table 3 shows the predicted MRR values, which were obtained by the ANN for test data.

$$
M S E=\frac{1}{Q} \sum_{k=1}^{Q} e(k)^{2}=\frac{1}{Q} \sum_{k=1}^{Q}[t(k)-y(k)]^{2}
$$


Where $e(k)$ the error between the target and ANN output, $t(k)$ target output, $y(k)$ ANN output value, and $Q$ is the number of total data [30]

Table.3 ANN trained values of MRR with experimental results

\begin{tabular}{|c|c|c|c|}
\hline $\begin{array}{c}\text { Expt. } \\
\text { No. }\end{array}$ & $\begin{array}{c}\text { Experimental } \\
\text { MRR } \\
(\mathbf{g} / \mathbf{m i n})\end{array}$ & $\begin{array}{c}\text { ANN } \\
\text { Model } \\
\text { MRR } \\
(\mathbf{g} / \mathbf{m i n})\end{array}$ & $\begin{array}{c}\text { Deviation } \\
\mathbf{( \% )}\end{array}$ \\
\hline 1 & 0.0468 & 0.0462 & 1.28 \\
\hline 2 & 0.0470 & 0.0462 & 1.70 \\
\hline 3 & 0.0465 & 0.0470 & -1.07 \\
\hline 4 & 0.0466 & 0.0470 & -0.85 \\
\hline 5 & 0.0401 & 0.0397 & 0.99 \\
\hline 6 & 0.0404 & 0.0397 & 1.73 \\
\hline 7 & 0.0420 & 0.0409 & 2.61 \\
\hline 8 & 0.0422 & 0.0409 & 3.08 \\
\hline 9 & 0.0368 & 0.0390 & -5.97 \\
\hline 10 & 0.0367 & 0.0390 & -6.26 \\
\hline 11 & 0.0581 & 0.0596 & -2.58 \\
\hline 12 & 0.0582 & 0.0596 & -2.40 \\
\hline 13 & 0.0422 & 0.0422 & 0.00 \\
\hline 14 & 0.0420 & 0.0422 & -0.47 \\
\hline 15 & 0.0702 & 0.0669 & 4.70 \\
\hline 16 & 0.0699 & 0.0669 & 4.29 \\
\hline 17 & 0.0703 & 0.0701 & 0.28 \\
\hline 18 & 0.0704 & 0.0701 & 0.42 \\
\hline
\end{tabular}

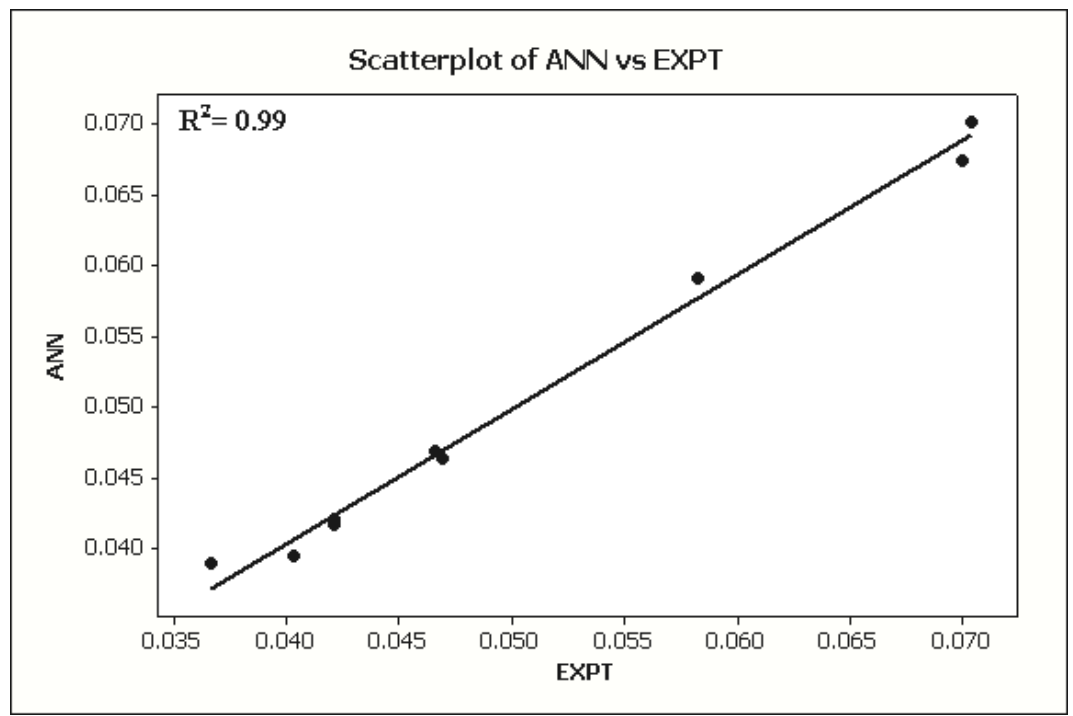

Fig. 4 Comparison of predicted values of MRR with experimental MRR (trained)

The values of MRR obtained from the trained ANN model are compared with experimental MRR is given in Table 3. The error can be calculated using equation (5). It can be found that the trained values and experimental values have very less deviation (average error of $2.58 \%$ ). The 
trained data are compared with experimental data is shown in Fig. 4.It is clear that the experimental data agree very well with trained ANN data.

The experimental set consists of 27 data points, of which 18 data points were used for training the network and 9 data points were chosen randomly for testing the performance of the trained network. After the network has successfully completed the training stage, it was tested with the experimental data that were not present in the training data set. The results obtained were compared using statistical methods given in Table 4. It is observed that the mean deviation of the predicted MRR and experimental MRR is very less. Fig.5 and Fig.6 shows the comparison of measured and predicted data of the MRR for the training and testing stages, respectively. It is found that there is very less deviation between predicted and experimental values of MRR. Thus, the ANN model can give adequate predictions of the MRR for the conditions considered.

Table.4 ANN tested values of MRR with Experimental results

\begin{tabular}{|c|c|c|c|}
\hline $\begin{array}{c}\text { Expt. } \\
\text { No. }\end{array}$ & $\begin{array}{c}\text { Experimental } \\
\text { MRR } \\
(\mathbf{g} / \mathbf{m i n})\end{array}$ & $\begin{array}{c}\text { ANN } \\
\text { Model } \\
\text { MRR } \\
(\mathbf{g} / \mathbf{m i n})\end{array}$ & $\begin{array}{c}\text { Deviation } \\
(\mathbf{\%})\end{array}$ \\
\hline 1 & 0.0469 & 0.0464 & 1.06 \\
\hline 2 & 0.0466 & 0.0468 & -0.42 \\
\hline 3 & 0.0403 & 0.0394 & 2.23 \\
\hline 4 & 0.0421 & 0.0416 & 1.18 \\
\hline 5 & 0.0366 & 0.0389 & -6.28 \\
\hline 6 & 0.0582 & 0.0591 & -1.54 \\
\hline 7 & 0.0421 & 0.0420 & 0.23 \\
\hline 8 & 0.0700 & 0.0674 & 3.71 \\
\hline 9 & 0.0704 & 0.0701 & 0.42 \\
\hline
\end{tabular}

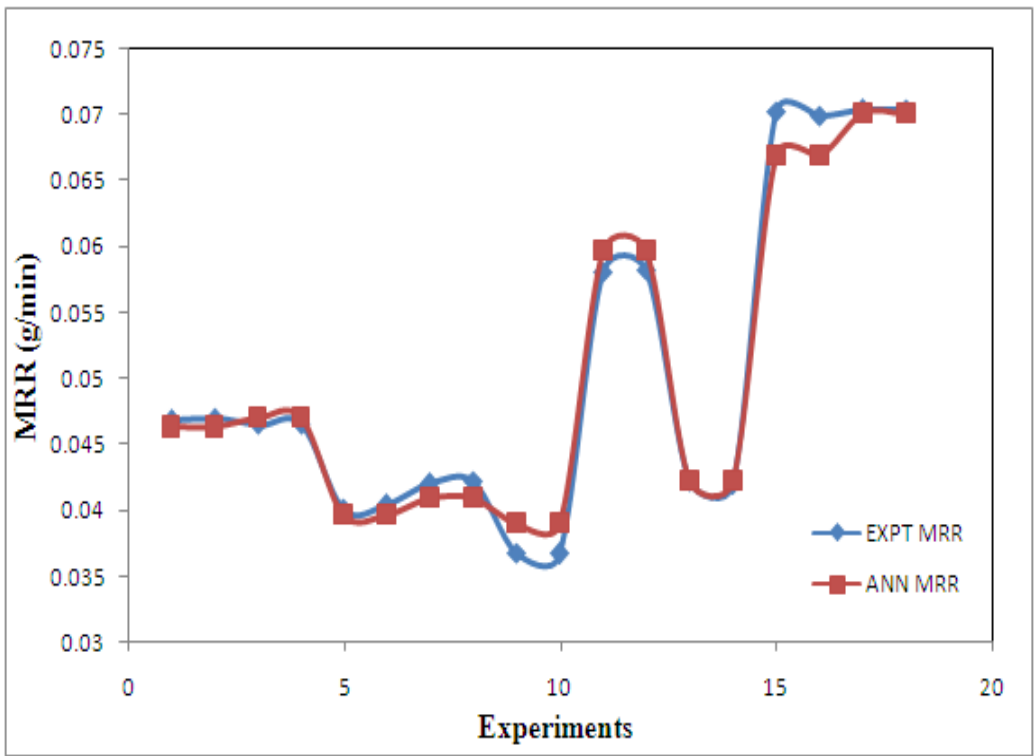

Fig .5 Comparison of predicted ANN model with experimental results (trained) 


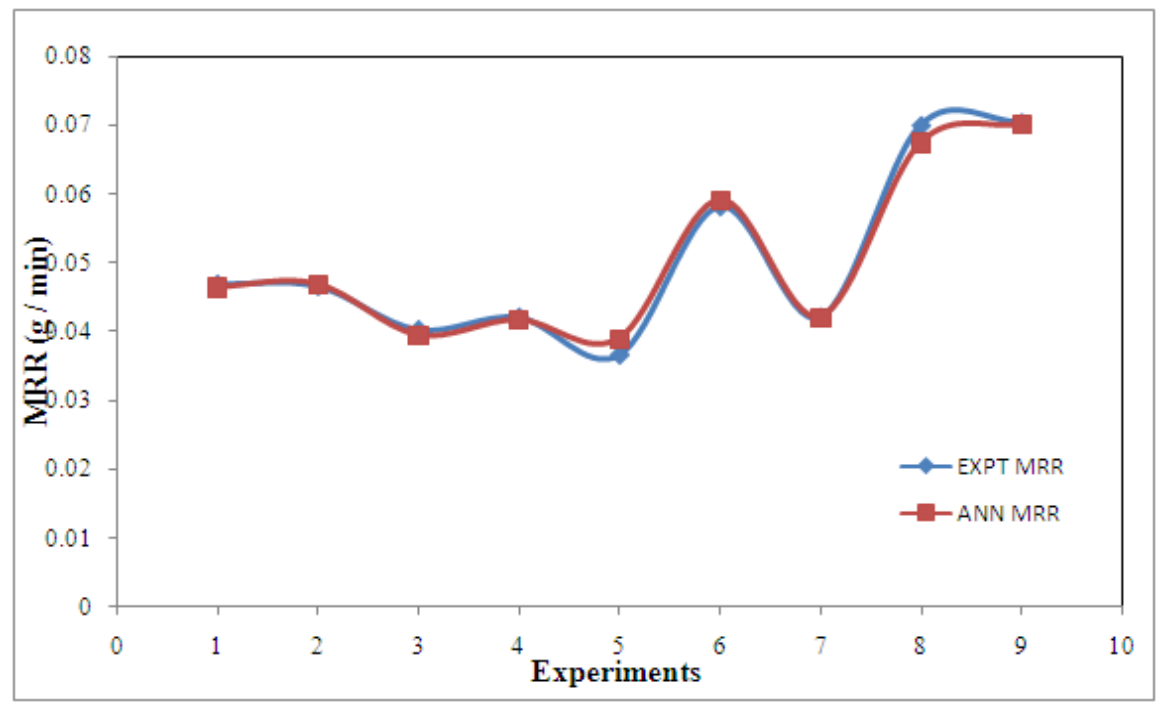

Fig.6Comparison of predicted ANN model with experimental results (tested)

\subsection{Determination of optimal combination of process parameters}

In order to study the significance of the process parameters towards MRR, statistical software Minitab 16 with ANOVA tool was used. The results of ANOVA for the response MRR is shown in Table. 5.

Table.5ANOVA of MRR for $\mathrm{NaOH}$

\begin{tabular}{|l|l|l|l|l|l|l|l|}
\hline Source & DF & Seq SS & Adj SS & Adj MS & F & P & $\begin{array}{l}\text { Contribut } \\
\text { ion (\%) }\end{array}$ \\
\hline Concentration & 2 & 0.0049682 & 0.0049682 & 0.0024841 & 21.64 & 0.044 & 40.14 \\
\hline Voltage & 2 & 0.0029576 & 0.0029576 & 0.0014788 & 12.88 & 0.072 & 17.86 \\
\hline SOD & 2 & 0.0042242 & 0.0042242 & 0.0021121 & 18.40 & 0.052 & 36.22 \\
\hline Error & 2 & 0.0002296 & 0.0002296 & 0.0001148 & & & 5.76 \\
\hline Total & 8 & 0.0123796 & & & & & \\
\hline
\end{tabular}

Table.6 Response table based on $\mathrm{S} / \mathrm{N}$ ratio of MRR for $\mathrm{NaOH}$

\begin{tabular}{|c|c|c|c|}
\hline \multirow{2}{*}{ Levels } & \multicolumn{3}{|l|}{ Factors } \\
\cline { 2 - 4 } & Concentration & Voltage & SOD \\
\hline 1 & -26.169 & -25.372 & $-21.108^{*}$ \\
\hline 2 & -23.520 & -23.020 & -21.799 \\
\hline 3 & $-19.855^{*}$ & $-21.152^{*}$ & -26.636 \\
\hline Delta & -6.3140 & -4.2200 & -5.5280 \\
\hline Rank & 1 & 3 & 2 \\
\hline
\end{tabular}

From the main effect plot, it is observed that the MRR increases with the increase of Electrolyte concentration and Voltage. This is because of the density of the spark is more for the larger value of voltage and higher concentration of electrolyte. The electrochemical reaction and hydrogen bubble generation increases with increase of voltage and electrolyte concentration which leads to increase of MRR. On examining the percentage of contribution of factors through ANOVA from Table. 5 it can be seen that electrolyte concentration has the highest contribution of $40.14 \%$. Thus electrolyte concentration is more significant factor which influences the increase of MRR. It can 
also be observed that the other parameters like SOD (36.22\%) and voltage (17.86\%) have less significance. It is also evident that MRR is maximum at 30\% of electrolyte concentration, at 60 volts and $0.03 \mathrm{~mm}$ of SOD.

\subsection{Confirmation Test}

After identifying the most influential parameters, the final phase is to verify the experimental results (MRR) by conducting the confirmation test. The $\mathrm{A}_{3} \mathrm{~B}_{3} \mathrm{C}_{1}$ is an optimal parameter combination of the ECDM process. The overall mean of $\eta$ associated with $\mathrm{k}$ number of trials is computed with Equation (7) as given below;

$$
m=\frac{1}{k} \sum_{k=1}^{k=9} \eta_{k}
$$

The predicted optimal value for multiple responses can be calculated using the equation

$$
\eta_{\text {opt }}=m+\sum_{i=1}^{0}\left(\left(m_{i}-m\right)\right.
$$

Where $m$ is the total mean of the multiple response of $\mathrm{S} / \mathrm{N}$ ratio at the optimal level and $m_{i}$ is the $\mathrm{S} / \mathrm{N}$ ratio at optimal parameter.

The predicted optimal value of response can be calculated using the Equation (8). The predicted optimal values for responses (MRR) are shown in Table. 6. In order to validate, the experiment, four trials were conducted according to the optimal parameters levels $\left(\mathrm{A}_{3} \mathrm{~B}_{3} \mathrm{C}_{1}\right)$ and the corresponding values of performance measures were taken. Table. 7 shows the predicted MRR and MRR obtained from the experiment. It may be noted that there is good agreement between the estimated value (-15.753) and the experimental value (-16.056). Therefore, the parameter combination $\mathrm{A}_{3} \mathrm{~B}_{3} \mathrm{C}_{1}$ of the ECDM process is treated as optimal. The optimal combination $\mathrm{A}_{3} \mathrm{~B}_{3} \mathrm{C}_{1}(30 \%$ of electrolyte concentration, $60 \mathrm{~V}$ of voltage, $0.03 \mathrm{~mm}$ of SOD) is also confirmed by ANOVA.

Table.7 Results of confirmation Test

\begin{tabular}{|l|l|l|l|l|}
\hline Particulars & $\begin{array}{l}\text { Performance } \\
\text { Characteristic }\end{array}$ & $\begin{array}{l}\text { Optimal } \\
\text { setting }\end{array}$ & $\begin{array}{l}\text { Predicted } \\
\text { optimal }\end{array}$ & $\begin{array}{l}\text { Experimental } \\
\text { optimal }\end{array}$ \\
\hline $\begin{array}{l}\text { Response } \\
\text { optimization }\end{array}$ & MRR & $\mathrm{A}_{3} \mathrm{~B}_{3} \mathrm{C}_{1}$ & -15.753 & -16.056 \\
\hline
\end{tabular}

\section{Conclusions}

In the present paper, the empirical models have been developed for grooving process of ECDM using Multiple Regression Analysis. The ANN model developed to predict the MRR using MATLAB Neural Network Toolbox7.10 (R2010b). From the experimental investigation, the following conclusions are derived

- It has been observed that, there is good agreement between the predicted model and the experimental results.

- According to results of the MSE, the ANN model produced the better prediction for MRR compared to the Regression model. It is clear that, the developed ANN models 
can be used to estimate the results of ECDM for the given range of process parameters.

- Through ANOVA, the percentage of contribution of the electrolyte concentration is more compared to other parameters. Hence, electrolyte concentration is the significant factor for the ECDM for the maximization of MRR for grooving.

- The combination of $\mathrm{A}_{3} \mathrm{~B}_{3} \mathrm{C}_{1}$ shows the largest value of the multi-response $\mathrm{S} / \mathrm{N}$ ratio for the factors $\mathrm{A}, \mathrm{B}$, and $\mathrm{C}$ respectively. Therefore, $\mathrm{A}_{3} \mathrm{~B}_{3} \mathrm{C}_{1}$ ( $30 \%$ of electrolyte concentration, $60 \mathrm{~V}$ of voltage, $0.03 \mathrm{~mm}$ of $\mathrm{SOD}$ ) is the optimal parameter combination of the ECDM for soda lime glass

- From the investigation, the two models of ECDM process can be strongly recommended to predict the MRR for grooving.

\section{REFERENCES}

[1] I. Basak and A. Ghosh "Mechanism of spark generation during electrochemical discharge machining, a theoretical model and experimental verification", Journal of Material Processing Technology, Vol. 62, 1996, pp. 46-53.

[2] N. Gautam and V. K. Jain, "Experimental investigations into ECSD process using various tool kinematics", International Journal of Machine Tools and Manufacture, Vol 38, 1998, pp. 15-27.

[3] B. Bhattacharyya, B. N. Doloi and S.K. Sorkhel, "Experimental investigations into electrochemical discharge machining (ECDM) of non-conductive ceramic materials", Journal of Material Processing Technology, Vol95, 1999, pp. 145-154.

[4] Alakesh Manna, "An Experimental Investigation during Micro Machining ofE-Glass-Fibre-Epoxy Composite on Developed Electrochemical Spark Machining Setup46", International Journal of Manufacturing, Materials, and Mechanical Engineering, Vol 2(2), April-June 2012 , pp. 46-60.

[5] Dae-Jin Kim, YoominAhn, Seoung-Hwan Lee, Yong-Kweon Kim, "Voltage pulse frequency \& duty ratio effects in an electrochemical discharge micro drilling process of Pyrex glass", International Journal of Machine Tools and Manufacture, Vol 46, 2006, pp. 1064-1067.

[6] H. Tsuchiya, T. Inoue, M. Miyazaki, "Wire electro-chemical discharge machining of glass and ceramics", Proceedings of the Fifth International Conference on Production Engineering, Tokyo, 1984, pp. 413-417.

[7] Y.P. Singh, Vijay. K. Jain, Prashant Kumar,D.C. Agarwal.”, Machining piezoelectric (PZT) ceramics using electro chemical spark machining (ECSM) process"., Journal of material processing technology, Vol 58, 1996, pp.24-31.

[8] J.W.Liu, T.M.Yue, Z.N.Guo, "An analysis of the discharge mechanism in electrochemical discharge machining of particulate reinforced metal matrix composites", International Journal of Machine Tools and Manufacture, Vol 50,2010, pp. 86-96.

[9] V.K. Jain and S. Adhikary, "The mechanism of material removal of electrochemical spark machining of quartz under different polarity conditions", Journal of materials processing technology. Vol 200, 2008, pp. 460-470.

[10] A. Kulkarn, R. Sharan and G.K. Lal, "An experimental study of discharge mechanism in electrochemical discharge machining”, International Journal of Machine Tools and Manufacture,Vol 42 , 2002, pp. 1121-1127.

[11] V. Fascio, R. Wüthrich and H. Bleuler, "Spark assisted chemical engraving in the light of electrochemistry", ElectrochimicaActa, Vol49, 2004, pp. 3997-4003.

[12] R. Wuthrich, U. Spaelter, Y. Wu and H. Bleuler. "A systematic characterization method for gravity-feed micro-hole drilling in glass with spark assisted chemical engraving (SACE)", Journal of Micromechanics and Microengineering, Vol16, 2006, pp. 1891-1896.

[13] K. Sanjay Chakand , P. Venkateswara Rao, "The drilling of A12O3 using a pulsed DC supply with a rotary abrasive electrode by the electrochemical discharge process", International Journal of Advanced Manufacturing Technology,Vol39,2008, pp. 633-64.

[14] LeszekKudla, "Investigation into electrochemical discharge machining of Micro- holes", Journal of Automation, Mobile Robotics and Intelligent Systems, Vol 3,No 4, 2009.

[15] M. Schopf, Beltrami, M. Boccadoro, D. Kramer, "ECDM (Electro Chemical Discharge Machining), a New Method for Trueing and Dressing of Metal Bonded Diamond Grinding". 
[16] Debasish Nandi, AsitBaranPuri, IndrajitBasak, "Behaviour of bubbles generated in electro chemical discharge machining",International Journal of Engineering Science and Technology (IJEST), Vol. 3 No.12, 2011, ISSN: 0975- 5462, pp. 8274-8280.

[17] Xuan Doan Cao, Bo Hyun Kim and Chong Nam Chu, "Micro-structuring of glass with features less than $100 \mu \mathrm{m}$ by electrochemical discharge machining". Precision Engineering.Vol 33, 2009, pp. 459465.

[18] V. Raghuram, T. Pramila,Y.G. Srinivasa and K. Narayanasamy, "Effect of the circuit parameters on the electrolyte in the electrochemical discharge phenomenon", journal of materials processing technology,Vol 52, 1995, pp. 301-318.

[19] D.Jana ,AbouZiki, TohidFatanatDidar and Rolf Wuthrich, "Microtexturing surfaces on glass with spark assisted chemical engraving". International Journal of Machine Tools and Manufacture.Vol 57, 2012, pp. 66-72.

[20] Cheng-Kuang Yang, Kun-LingWu, Jung-ChouHung, Shin-MinLee, Jui-Che Lin and Biing-HwaYan, "Enhancement of ECDM efficiency and accuracy by spherical tool electrode", International Journal of Machine Tools and Manufacture, Vol 51, 2011, pp. 528-535.

[21] M.Coteaja, L.Slatineanu,O.Dodun, and C.Ciofu , "Electrochemical discharge machining of small diameter holes",International Journal of Material Forming,Vol 1, 2008, pp. 1327-1330.

[22] Min-Seop Han, Byung-Kwon Min, Sang Jo Lee, "Micro-electrochemical discharge cutting of glass using a surface-textured tool", CIRP Journal of Manufacturing Science and Technology, Vol 4, 2011, pp. 362-369.

[23] J.Z. Zhang, J.C. Chen and E.D. Kirby, "Surface roughness optimization in a end-milling operation using the Taguchi design method", Journal of Materials Processing Technology. Vol 184, 2007, pp. 233-239.

[24] N. Jagannatha, S. Somashekhar, Hiremath and K. Sadashivappa, "Analysis and parametric optimization of abrasive hot air jet machining for glass using taguchi method and utility concept".International Journal of Mechanical and Materials Engineering(IJMME),Vol 7(1), 2012, pp. 9-15.

[25] E.O. Ezugwua, D.A. Fadera, J. Bonneya, R.B.Dasilva and W.F.Salesa, "Modeling the Correlation between Cutting and Process Parameters in High Speed Machining of Inconel 718 Alloy Using An Artificial Neural Network", International Journal of Machine Tools and Manufacture, Vol.45, 2005, pp. $1375-1385$.

[26] IhsanKorkut, AdemAcir and Mehmet Boy, "Application of regression and artificial neural network analysis in modeling of tool-chip interface temperature in machining", Journal of Expert Systems with Applications, Vol 38,2011, pp. 11651-11656.

[27] G. Krishna Mohana Rao, G. Rangajanardhaa, D. Hanumantha Rao, M. Sreenivasa Rao, "Development of hybrid model and optimization of surface roughness in electric discharge machining using artificial neural networks and genetic algorithm”,Journal of materials processing Technology, Vol 209, 2009, pp. 1512-1520.

[28] T.K.K.R. Mediliyegedara, A.K.M. De Silva, D.K. Harrison, J.A. McGeough , “An intelligent pulse classification system for ECDM - a preliminary study", Journal of Materials Processing Technology, Vol 149, 2004, pp. 499-503.

[29] Ilhan Asiltürk, Mehmet Çunka, "Modeling and prediction of surface roughness in turning operations using artificial neural network and multiple regression method", Journal of Expert Systems with Applications, Vol 38, 2011, pp. 5826-5832.

[30] T. Findik, Tasdemir S, Sahin, "The use of artificial neural network for prediction of grain size of 174 pH stainless steel powders”. Sci. Res. Essays,Vol 5(11), 2010, pp. 1274-1283.

\section{Authors}

Sathisha N. Working as Associate professor in mechanical engineering department Alva's institute of engineering and technology, Moodabidri, Mangalore, India.He received the BE degree in Mechanical Engineering from Mysore University in the year 1994. M.Tech degree in Production engineering systems technology in the year 2000 and pursuing Ph.D. at visveswaraya technological university Belgaum. He has

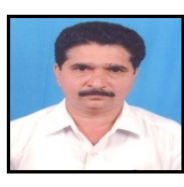
twenty years of teaching experience and published many papers in national and International conferences. His current research interest includes hybrid machining, advanced materials, robotics, mechatronics, MEMS and micromachining. 
Somashekhar S. Hiremath works as an Associate Professor and Head,Precision Engineering and Instrumentation Laboratory of Department of Mechanical Engineering at Indian Institute of Technology Madras, Chennai, Tamil Nadu, India. He received the Doctoral Degree in 2004 from Indian Institute of Technology Madras, Chennai, Tamil Nadu, India. As an academic credential he received Two National

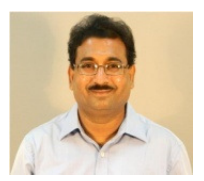

Awards: Innovative Student Project Award 2005 (Best PhD Thesis of the year 2004-2005 in the Department of Mechanical Engineering) from the Indian National Academy of Engineering (INAE), New Delhi and Prof. K. Arumugam National Award for Innovative Research Work in Engineering and Technology from Indian Society for Technical Education (ISTE), New Delhi. He has published many papers in National and International level. More than 100 papers in his credits. He has delivered more than 60 Invited talks on various topics of his research areas at Engineering Colleges, Universities, Research centres, Industries and conferences. Currently he is handling many Consultancy and Sponsored Projects of various industries and R\&D institutions of Defence, Government of India. His Current Research Areas are Mechatronic System Design-System Simulation and Modelling, Robotics, Finite Element Modelling - basically Fluid Structure Interactions, Micromachining, Advanced machining processes - basically Hybrid Processes. He has guided $1 \mathrm{Ph}$. D. and $2 \mathrm{MS}$ Thesis. Currently 5 Ph.D. Scholars and 2 MS Scholars are working under his guidance. Last but not the least he is a Member of Many Professional Bodies like Fluid Power Society, American Society for Precision Engineering and European Society for Precision Engineering and Nanotechnology (EUSPEN), Indian Society for Technical Education

ShivakumarJ. born on 11th of October 1966 completed his Bachelors degree in Engineering in Mechanical from Govt. BDT college of Engineering, Davangere affiliated to Mysore University in 1989, obtained his Masters degree in Machine Design from BMS college of Engg., Bangalore University in 1996, and pursued Ph.D from IIT Kharagapur in 2008. He is having total teaching experience of 24 years and presently he

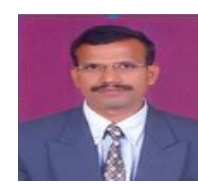
is serving as principal of Chhattisgarh Engineering College (CEC), durg, Chhattisgarh, India. He is life member of professional bodies VIZ., Indian society for Technical Education(ISTE)-New Delhi, Indian Society of Theoretical and Applied mechanics (ISTAM )-Kharagpur etc., His areas of interest are Mechanics and Machining of materials, Applied Mechanics, Smart materials,. He has published several research papers in International Journals, presented several papers in International and National conferences. 